\title{
GMD: Its Function and Its History
}

\section{Mauro Guerrini}

To cite this article: Mauro Guerrini (2004) GMD: Its Function and Its History, Cataloging \& Classification Quarterly, 38:2, 61-74, DOI: 10.1300/J104v38n02 06

To link to this article: https://doi.org/10.1300/J104v38n02_06

$$
\text { 曲 Published online: } 24 \text { Oct } 2008 .
$$

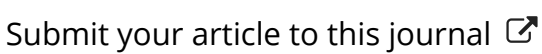

$$
\text { Џll Article views: } 127
$$

Q View related articles $\sqsubset$

4 Citing articles: 7 View citing articles 


\title{
GMD: Its Function and Its History
}

\author{
Mauro Guerrini
}

\begin{abstract}
The history, scope, and functions of the General Material Designation (GMD) are reviewed. Reasons for difficulties in using GMDs, the hybrid nature of GMDs, and their functional nature are examined. Future uses of GMD in an international context are discussed. Agreement exists that a sound definition for the "mode of expression" is still needed. [Article copies available for a fee from The Haworth Document Delivery Service: 1-800-HAWORTH. E-mail address: $<$ docdelivery@haworthpress.com>Website: <http://www.HaworthPress.com> (C) 2004 by The Haworth Press, Inc. All rights reserved.]
\end{abstract}

KEYWORDS. General Material Designation, GMD, GMD-SMD, mode of expression, non-book materials, AACR, FRBR

\section{GMD: AN INTRODUCTION}

The use of General Material Designation (GMD) is optional, but recommended, and is considered "especially useful" for non-book materials included in integrated catalogues or bibliographies (1.2.2.): it has the function "to indicate, in general terms and at an early point in the description, the class of materials to which the item belongs." GMD applies to the primary component of an item and is formulated in the language of the bibliographic agency, either immediately after the first element of the proper title, between square brackets, or after the first element of the first title, whether the document contains many works without a proper title. GMD immediately indicates the class

Mauro Guerrini, PhD, is Professor, Department of Medieval and Renaissance Studies, University of Florence, Piazza Bruneschelli, 4, I-50121, Florence, Italy (E-mail: m.guerrini@leonet.it).

Cataloging \& Classification Quarterly, Vol. 38(2) 2004

http://www.haworthpress.com/web/CCQ

(C) 2004 by The Haworth Press, Inc. All rights reserved.

Digital Object Identifier: 10.1300/J104v38n02_06 
of the item, informs that the described material is an electronic resource, a videorecording or else, to let the user select the class of document he/she wants. GMD underlines the structural consistence of the catalogue, which describes works reproduced on different media and aims to distinguish them in a small number of classes. GMD allows for materials available in different media to be distinguished when searching and browsing the catalogue. ${ }^{1}$

\section{HISTORY OF GMD}

GMDs first appeared in 1967, within AACR1, and were defined as 'qualifiers,' for they were due to be added to titles of motion pictures and filmstrips (Ch. 12) and phonodisc, phonowire and phonotape (Ch. 14) in order to distinguish them from books with the same title in the catalogue. ${ }^{2}$ In 1975, at the time of the revision of Chapter 12 and Chapter 14 of AACR1, the first two qualifiers ("motion pictures" and "filmstrips") were inserted in a longer list of so-called "medium designators," while the qualifiers "phonodisc," "phonowire" and "phonotape" were replaced by a single term ("Sound recording"), illustrating indecision about the appropriate level of specificity for the term.

The term "General Material Designation" first appeared in 1977 both in the ISBD(G) and ISBD(NBM). Starting from 1977, GMD was optional and in AACR2, from 1978 on, was provided in two GMD lists, List 1 for Britain and List 2 for North America.

GMDs did not have a large application and success, probably because of the differences between the two lists, the optionality for the use of GMD, and the less than enthusiastic reception of the Library of Congress. In the Cataloging Service Bulletin of the Fall 1977, the Library of Congress expressed its opinion on GMDs in these terms: "The Library of Congress, the British Library, the National Library of Australia, and the National Library of Canada have already agreed that bibliographic records created by each in machine readable form would include the information necessary to derive the appropriate GMD. Each institution, however, will establish its own policy for displaying the GMD." Further, in the same bulletin one can read:

The Library of Congress is of the opinion that GMDs are less satisfactory than the specific designations that are found in the physical description area. For example, the use of the GMD "Sound recording" may distinguish a sound manifestation of a work from other manifestations (a motion picture, printed music, etc.), but it gives no clue as to which of the various, quite different forms of sound recordings the particular item might be. 
The physical description area must be consulted if one wants to know whether disc equipment of the various tape players will be needed for playback. There is also a kind of favouritism accidentally at work in the choices of the terms that make up the taxonomy of GMDs: some classes of materials are called what they are, e.g., "filmstrip" and "microscope slide," while others are designated by a more or less artificial term that is not only not in common use but conveys little information, e.g., "art original," "sound recording," and "text." This unequal treatment per se is unsatisfactory. Ideally, GMDs should be discarded and the physical description relied upon for information about an item's nature.

Even if GMDs have been used since 1978, it is clear both that their use was not completely agreed upon and that it came not from a theoretical study but only in response to a practical question (to distinguish or qualify different resources within the same catalogue). Nevertheless, twenty-five years after its creation, opinion still prevails to sustain its importance and usefulness in the context of WebOpacs. GMD is a great help for remote users, who are increasing in numbers.

\section{THE SCOPE OF GMDS}

As seen earlier in the introduction, the clear purpose is to help the user, by giving him/her the necessary information for selecting more quickly the items of interest and to discard those that create only noise, by means of declaring at the very beginning of the bibliographic record the "type of document" (or the "class of material"). ${ }^{3}$

A recent study of Jean Weihs had the scope to verify whether the GMDs "developed in the middle years of the twentieth century were still a meaningful addition to the bibliographic record."4 Even if the research demonstrated that about the GMDs there was not agreement on their utility and practical use, the conclusion drawn "from the solutions responses is that gmds are still a useful addition to the bibliographic record, but the present list of gmds needs to be modified or rethought." Many of the respondents stressed that the importance of GMDs is due to the increasing use of Web catalogues, but we could also add the increasing proportions of catalogues and the larger use of non-book materials.

Sten Hedberg developed a study on the role and application of the Medium Specific Designators, presented at the 64th IFLA General Conference; he underscored that: 
[T] he role of designations in bibliographical descriptions is to help the user to get a correct image of the document described. In most media types, no designations or very few are required: in printed text material, only the various physical carriers require designations. Or various other media types, a GMD after the title proper enables the user's mind to understanding further special elements, such as the scale of the maps, etc, which may in their turn use designations.

Even if Hedberg analysed mainly the use of GMDs and SMDs for electronic resources, he remarks that "in general, designations are based on common language, that of the cataloguer, and chosen from a list of preferred terms without respect to designations used on the item." 5

\section{GMD ISSUES}

The use of GMD must be considered difficult for the following reasons:

1. its hybrid, "classificatory" 6 and functional nature;

2. the existence of many different lists; ${ }^{7}$

3. the incomprehensibility of some terms for cataloguers and/or users; ${ }^{8}$

4. the difficult application for multiple characteristic resources, because many terms are too general;

5. its optional application;

6. its display in the OPAC.

As one can see, issues 2, 3 and 5 could easily be solved, if only an answer could be found to the question of the real nature of GMD and to its consistent, consequent application.

As noted above, as conclusion of her research about the use of GMDs, Jean Weihs stresses that GMDs are still useful, but also that "the present list of gmds needs to be modified or rethought."

\section{THE HYBRID NATURE}

Tom Delsey ${ }^{9}$ gives a sound demonstration of the large inconsistency of the list of GMDs, which includes terms referring to the class of material, but also to physical format, form of carrier and notation. As the definition of GMD refers directly to the "class of material," to better understand the use of GMD one needs to make clearer the concept of "class of material." In Tom Delsey's 
model of AACR the class of material "is the broad class or specific class of materials to which an item belongs." 10 Additionally, in AACR

Class of material is a bibliographic entity that functions as a means of organizing the rules for description. Documents and document parts are assigned to a specific class of materials based normally on the form of the physical carrier of the document or document part. Specific classes are in turn grouped to form a broad class of materials, normally on the basis of common physical characteristics linking the specific classes in the group. ${ }^{11}$

So, if we agree to relate the GMD concept to the class of material, we can easily see that a "simple" issue turns into a great question. Actually, Delsey raises the question of the class of material in these terms: "while the form of the physical carrier is in many cases the principal criterion for determining the broad class of materials to which an item belongs, there are in fact other criteria at play in defining the scope of those classes." Besides the form of the physical carrier, some classes of material are identified on the basis of the intellectual or artistic content of the item, or also by the form of expression. Delsey's analysis succeeds in pointing up that "the concept of CLASS OF MATERIALS that provides the underlying structure for the rules in Part I is more complex than it might appear on the surface, and [...] determining the class of materials to which an item belongs is not synonymous with determining the form of the physical carrier." 12

We could add that, as the GMD definition is founded on the class of materials concept, it would have been very hard to give a consistent and clear application of GMD till now!

\section{THE FUNCTIONAL NATURE OF GMD}

Ann Huthwaite, in a posting titled Class of Material Concept and GMDs to the JSC for Revision of AACR, pointed out that the main problem with class of material and GMDs is that the new wording for rule 0.24 did not succeed in really changing the previous principle that "the description of a physical item should be based in the first instance on the chapter to which it belongs" and this still leads the cataloguer to try to determine "the predominant class to which an item/resource belongs." 13

To avoid such misinterpretation of the new rule 0.24 , Huthwaite proposes to abandon completely the concept of class, and to consider item/resources as having multiple characteristics all bearing equal weight. ${ }^{14}$ 
The reason why cataloguers did not abandon the concept of class of material is that "there are a number of methods of procedure which assume that an item/resource belongs to a predominant class [...] these are: the choice of the chief source of information and prescribed sources of information; the choice of a general material designation; and, the recording of area 5 (in particular, the specific material designation."

This background paper is chiefly devoted to Huthwaite's proposal for a new use of GMDs. Huthwaite supports Barbara Tillett's suggestions to (1) use a device in the bibliographic record representing the mode of expression, (2) move terms representing physical format and form of carrier to area 5, or to notes.

As it will be useful to revise AACR in the context of the FRBR model, a further suggestion is "to consider the general material designation as an expression-level indicator, and the specific material designation as a manifestation-level indicator" and consequently to split List 2 to either expression-level indicators or to description at the manifestation level.

In a comment to Ann Huthwaite, Tom Delsey stresses that "Regardless of whether the GMD is recorded and displayed as part of the description per se or as part of an organizing element, it would be advisable to align the list of GMDs with mode of expression (i.e., to have it reflect content rather than carrier)." 15

To sum up as the possible uses of the GMDs in the future, Jean Weihs ${ }^{16}$ suggested three options:

1. GMD is conceived as a general early warning signal, so that it should not be formulated by the specific terminology of List 2, but rather in more general designations. ${ }^{17}$

2. GMD should be very specific (such as "DVD" and "CD-ROM"), in order to let the users easily understand the specific format of the item described in the bibliographic record.

3. GMD should be qualified (e.g., [Electronic Resource (DVD)] or [Electronic Resource (CD-ROM)], in order to grant a larger consistency to the catalogue reusing the existing GMD, or many of them, but with qualifiers to better match specificity and user friendliness.

Each of these options could be satisfactory, but the question is to define, with the utmost precision, the meaning, the content and the use of the GMD before defining its wording and its position within the bibliographic record.

Before the study of Jean Weihs, the ALCTS CCS Committee on Cataloging: Description \& Access, in the frame of the analysis for the revision of Rule 
0.24 , examined also the GMD issue and concluded: "In creating cataloguing examples of items with multiple characteristics [...] and in carrying out experiments in reorganization based on ISBD area [...], it quickly became apparent that one of the most intractable content-carrier problems in AACR2R is presented by the GMD. This is a problem that is not going to go away under any of the proposed options, and probably needs to be addressed independently as a problem in its own right." 18

Also the CC:DA proposed these "possible options [...]:

A. Provide a table of precedence to support the current approach requiring choice of a single GMD from the current list.

B. Allow the formulation of a compound GMD when required [...]

C. Abandon the use of the GMD. This would require deletion of rule 1.1C and its counterparts in other chapters [... $]^{19}$

D. If the GMD is abandoned, consider transferring the "early warning" function of the GMD to Area 3 [...]

E. Continue to use the single GMD as is in AACR2R, but allow use in Area 3 of whatever combinations of GMD terms are necessary to bring out aspects of the item not covered by the single GMD chosen."

During the First IFLA Meeting of Experts on an International Cataloguing Code, held in July 2003 at Frankfurt am Main, Germany, the Working Group 5 on Uniform Titles and GMDs, when discussing GMDs at the Expression Level, agreed on these basic topics about the GMD:

After a thorough discussion the group decided, that designations pertaining to the form/mode of expression often provide useful information and probably should be retained. The group looked at two lists of candidate terms, one from FRBR and the other one suggested by Tom Delsey developed as a possible replacement for AACR part 1.

FRBR modes of expression:

\author{
Alpha-numeric notation \\ Music notation \\ Other notation (e.g., choreographic) \\ Sound \\ Still image \\ Moving image \\ Three-dimensional object \\ Combination of above
}


List of Tom Delsey:

Text

Music

Cartographic resource

Graphic resource

Three-dimensional resource

Sound recording

Moving images resource

Data

Software

Mixed content resource

Neither list was found to be entirely satisfactory, but both provided the desirable level of generality.

While the former list is extracted from FRBR report, we must note that the latter can't be correctly defined List of Tom Delsey. In fact, as Tom Delsey clarified,

It should be noted [. . . ] that the list I proposed for a re-organization of Part 1 of AACR2 was intended to serve as a list of chapter headings, not specifically as a list of GMDs. Granted, the list of chapters I proposed for the section on "content" was intended to reflect "mode of expression" and I have also suggested aligning the list of GMDs with "mode of expression," but I did not actually develop a list of proposed GMDs. I think one needs to look at the terms appropriate for chapter headings and the terms used as GMDs as two separate issues, even though they both have a connection with mode of expression. I also think we should not make an assumption that the kinds of content covered by a single chapter would necessarily all be designated by the same GMD. ${ }^{20}$

\section{A THEORETICAL CONTRIBUTION}

Should we maintain the existing definition, by which GMD should "indicate, in general terms and at an early point in the description, the class of materials to which the publication belongs"?

If one agrees that GMDs are related to the class of materials or to the "mode of expression," the focus of the question shifts to these concepts; as 
seen above, they are not clear and their meaning and use need further investigation.

In his contribution to Ann Huthwaite's analysis, Delsey describes the class of material issue in the context of a general re-organisation of Part 1 of AACR to include five sections: content description, technical description, mode of issuance, unpublished resources, analytics and multilevel description. Delsey proposes to separate GMD from the class of material concept ${ }^{21}$ and to relate it to the "mode of expression," that Barbara Tillett stresses to consider the same as FRBR's "form of expression." 22 Whether we read FRBR's definition for the form of expression ("the means by which the work is realized (e.g., through alpha-numeric notation, musical notation, spoken word, musical sound, cartographic image, photographic image, sculpture, dance, mime, etc."), ${ }^{23}$ we could find hard to understand, or to clarify, the correct relationship between the objects of the list and the content; this definition, even if sound per se, doesn't work for the issue of the GMD.

What exactly should we intend for "mode of expression"? Delsey offers some clues about the "mode of expression" in his description of the re-organisation of Part 1: "The chapters pertaining to 'content' be organized according to classes that reflect the mode of expression (text, musical notation, recorded sound, etc.)." As one can see, there is not a criterion for defining a class, but a short list of examples from which the abstraction of a criterion (if a criterion does or must exist) ${ }^{24}$ is more difficult than it appears at first sight (nor the complete list of the table of contents helps more). To clarify, Delsey adds: "Note that 'electronic resources' are not treated as a class in this section. From a content perspective, electronic texts would be treated simply as texts, electronic music simply as music, etc. Two new classes (data and software) have been added to cover content that uses modes of expression distinct from those covered by other chapters. A separate class has also been added for mixed content." 25

As seen above, the list of Chapters for the revision of AACR is not a list of GMDs, but as we agree to adopt a content perspective in the analysis of the GMD issue, at the moment this list seems preferable to the FRBR's list.

Nevertheless, the 'content perspective' is not completely satisfactory nor consistent for the application to GMD. If we confront the definition of graphic (the art or science of drawing a representation of an object on a two-dimensional surface) with a cartographic resource, we can easily find that, from a content perspective, the latter is a species of the genus graphic (the adjective carto-graphic could give a clue, too).

If we reflect on sound recordings, we can imagine both a recording of Mozart's Requiem and a recording of the reading of Dante's Inferno by Vittorio 
Gassman. In both cases we have a sound recording but, from a content perspective, how can we distinguish the former from a music (Ch. 3) or the latter from a text (Ch. 2)?

When we think about data (factual information), how can we distinguish them from a (very tedious) text? And what about software (a sequence of coded instructions that can be inserted in a mechanism as a computer) that differs very little, in a content perspective, from another very tedious text?

As suggested by Tom Delsey, we could divide the issues of GMD in two steps: the level of specificity to assign to GMD and the list of terms to adopt, but it's hard to say which step is less difficult.

As to these steps, we can sum up that:

a. the only clear scope is to help the user to identify and select searched objects; ${ }^{26}$

b. GMD could be related to the 'content';27

c. GMD is to be considered a part of the couple GMD-SMD, and what will be inserted in the gender level must be excluded from the species level;

d. Chosen terms must be individuated by a criterion that lets the cataloguer assign uniquely any object to its class.

We can conclude that a sound definition for the "mode of expression" is still needed, and that it could greatly help to:

- give a meaningful consistence to the use of GMD, linking it directly to the uniform title for the work/expression level, and to move form of expression and form of carrier to other description areas;

- grant the use of a unique GMD for each document;

- assist both the user to better understand the content of the document and the cataloguer to find his/her way through the newly planned table of content of Part 1.

\section{AUTHOR NOTE}

The author must greatly thank both Barbara Tillett, who patiently revised the English text of the first draft and gave suggestions, and Tom Delsey, who integrated historical news and bibliographic references and helped very much for the considerations in the final paragraphs. The document was sent to the John Byrum and the ISBD Review Group. Thanks to Carlo Bianchini and Stefano Gambari for their help. The Italian edition will be published in the Festschrift Crocetti. Milano: Editrice bibliografica, 2004. 


\section{NOTES}

1. See Stefano Gambari, Mauro Guerrini, Definire e catalogare le risorse elettroniche. Una introduzione a ISBD(ER), AACR2 e metadati, Milano, Bibliografica, 2002, p. 102, modified.

2. The history section of this background paper is taken from Barbara Tillett, General Material Designations (GMDs).

3. The scope of helping the user may be "clear" while, as Tom Delsey observed, it still remains very obscure, as the definition of the concept "class of materials" is sometimes defined as "type of document."

4. Jean Weihs, General Material Designation in the Twentiy-First Century: Results of a Survey, available on line at: http://ublib.buffalo.edu/libraries/units/cts/olac/ capc/gmd.html (Last access: 12/09/03).

5. Sten Hedberg, Medium Specific Designations: Roles and Applications, available on line at: http://www.ifla.org/IV/ifla64/064-74e.htm (Last access: 15/09/03).

6. One could say that GMD seems more an element of a classification process rather than a descriptive element; so it could be better inserted in the semantic headings, or represented by an icon in the OPAC, rather than in the description areas. On this topic, see Appendix 1.

7. Since 1978 AACR2 presents two different lists of GMD: the British one prefers broader terms, the North American one is more detailed and could be preferred in a specialized library. Besides this, many bibliographic agencies integrated both the lists, created new entries, and amplied the lists often without taking care of consistence.

8. From Weihs's analyses it resulted that some terms are incomprehensible for both the cataloguers and the users.

9. Tom Delsey, The Logical Structure of AACR, available on line at: http://www. nlc-bnc.ca/jsc/aacr.pdf, (last access: 18/09/03).

10. Cfr. Delsey, The Logical . . , cit. p. 6. In the ISBDs one cannot find a definition for "class of material," even if it is the core concept for the GMD; we also must observe that the proposed definition, even if the only available till now, seems very vague, or at least sufficiently undefined to leave the reader uncertain between [bibliographic] material and [physical] material.

11. Delsey, The Logical . . , cit. p. 6.

12. Delsey, The Logical . . . , cit. p. 27.

13. Ann Huthwaite, Class of Materials Concept and GMDs., available on line at: http://www.ddb.de/news/ifla_conf_papers.htm (last access: 25/09/03). The problem arises "when an item/resource exhibits characteristics of more than one class, e.g., a digital map, and electronic journal, or a motion picture on DVD. Cataloguers are being forced to choose a predominant class when in fact no one set of characteristics is more important than another."

14. This seems not completely acceptable. A class is a set of objects identified by a criterion, a rule; the rule allows to define the class. An object can have multiple characteristics and those characteristics are, or may be, together or alone, a criterion for defining one or more classes. So any object must belong to one or more classes quite because it has some characteristics. The point is to choose, among all, only one characteristic (or criterion)that allows a unique decision about the assignment of one class to each object (e.g., the 'content perspective' proposed by Tom Delsey). 
15. Tom Delsey, Class of Materials Concept and GMDs: Comments to Ann Huthwaite, available on line at: http://www.ddb.de/news/ifla_conf_papers.htm (last access: 25/09/03), p. 2.

16. Jean Weihs, General Material Designation in the Twenty-First Century: Results of a Survey, available on line: <http://ublib.buffalo.edu/libraries/units/cts/olac/capc/ gmd.html> (Last access: 19/09/2003).

17. Verna Urbansky, in her response, points out: "While newer media might not be considered to be well served by the current system of GMDs, that would not necessarily indicate that the current systems does not continue to be useful in the control of the existing media. While the GMD computer file does not tell us all there is to know about the item, neither does the author entry tell us all there is to know about the content of a book. It is just one element. Meaning, in my mind at least, that the GMD is a component that should not be asked to bear too much descriptive burden, just like we would not expect to know the title or extent of the item merely by knowing the author's name."

18. ALCTS CCS Committee on Cataloging: Description \& Access, Overview and Recommendations Concerning Revision of Rule 0.24, available on line: http://www. libraries.psu.edu/tas/jca/ccda/docs/tf-024h7.doc (Last access: 11/11/03), pp. 7-8.

19. Currently, GMDs are required by ISBD, so if AACR2R abandoned the GMD, it would be failing to follow ISBD in this regard.) CC:DA suggests that this option should not be adopted without first studying the impact on existing libraries and systems. If MARC 21 coding is used differently by different systems to produce OPAC displays as a substitute for the GMD, there might be an undesirable loss of consistency across systems.

20. Tom Delsey, e-mail to Mauro Guerrini dated 30.10.03.

21. In Table 1 (Defined Scope for Classes of Materials) of Part 1 of the Logical structure of AACR, class of materials could be linked to the form of content (e.g., literary, cartographic, musical, cinematographic, graphic, etc.), or the form of expression (e.g., alpha-numeric, music notation, sound, still image, moving image, three-dimensional) or the form of physical carrier (e.g., book/pamphlet, sheet, globe, model, etc.).

22. As suggested by Barbara Tillett and confirmed by Tom Delsey. In fact, the JSC and Tom Delsey have used "mode of expression" to avoid confusion caused by the FRBR term "form of expression" where we now associate "form" with manifestation-it is intended that "mode of expression" is the same as FRBR's "form of expression." This has been confirmed also by Tom Delsey, in his e-mail dated 30 November 2003: "FRBR, on the other hand, uses the term 'form of expression,' and defines it as 'the means by which the work is realized (e.g., through alpha-numeric notation, musical notation ... . etc.).' The term 'mode of expression' seems to have emerged in the context of JSC discussions as a synonym for the FRBR term 'form of expression,' and so in responding to Anne Huthwaite's paper, I also used the term 'mode of expression' in place of 'form of expression.' (Just as an aside, I recall that in an early draft of FRBR we actually used the term 'mode of expression' and later changed it to 'form of expression.')."

23. FRBR, 4.3.2.

24. A class can also have an extensional definition (that is to say that is defined listing all its members), but this seems not to be the case, as we agree to adopt a content perspective.

25. Delsey, Class of Materials ..., cit., p. 3.

26. If we refer to FRBR, Table 6.2, we should substitute 'objects' with 'expressions'; however, we are actually still debating about these objects. 
27. If we agree on relating class of material and "mode of expression," and on assigning to the "mode of expression" a "content perspective" (differentiating it from the pure FRBR's form of expression), we must realize that we are operating at the work level. A logical consequence is that the content perspective suggests (as Barbara Tillett did) to remove the IGM from the area 1 and to link it to the uniform title for the work/expression level.

\section{APPENDIX 1}

Some libraries decided to run the way of the iconic solution to the representation of the GMD in the OPAC. In France, for instance, on BN OPALE-PLUS:

\begin{tabular}{|c|c|c|c|c|}
\hline & Icon & GMD & $\begin{array}{l}\text { Type of document term } \\
\text { used in the OPAC search }\end{array}$ & Notes on the icon \\
\hline 1 & & $\begin{array}{l}\text { [Enregistrement sonore] } \\
\text { Audioregistrazione }\end{array}$ & Documents sonores & Very clear \\
\hline 2 & & $\begin{array}{l}\text { [Images animées] } \\
\text { Videoregistrazione }\end{array}$ & Images animées & $\begin{array}{l}\text { Clear; otherwise it could } \\
\text { be used a reel and a } \\
\text { videocassette }\end{array}$ \\
\hline 3 & & $\begin{array}{l}\text { [Texte imprimé] } \\
\text { Testo a stampa }\end{array}$ & Livre & Very clear \\
\hline 4 & & $\begin{array}{l}\text { [Texte imprimé] } \\
\text { Testo a stampa }\end{array}$ & Périodique & $\begin{array}{l}\text { Icon is clear; not so } \\
\text { for the GMD }\end{array}$ \\
\hline 5 & & [Multimédia multisupport] & $\begin{array}{l}\text { Multimédia } \\
\text { multi-supports }\end{array}$ & $\begin{array}{l}\text { Icon not clear if } \\
\text { compared to } 1\end{array}$ \\
\hline 6 & & [Ressource électronique] & $\begin{array}{l}\text { Ressources } \\
\text { électroniques sur } \\
\text { support }\end{array}$ & $\begin{array}{l}\text { Clear, but it could be } \\
\text { added a CD-ROM }\end{array}$ \\
\hline 7 & & [Image fixe numérisée] & Images fixes & Not very clear \\
\hline
\end{tabular}

It is interesting to remember that the National Library of Canada uses:

[text (large print)] 


\section{APPENDIX 1 (continued)}

according to the National Library Service for the Blind and Physically Handicapped Guidelines, specifying which character dimensions are used in a printed text with large character (e.g., the largest amount of book has a character between 10 and 12 pt.; so 14 pt. is considered the small dimension for a large print material). 